\title{
O CENTENÁRIO DO XI DE AGOSTO: NOTAS SOBRE A DOCUMENTAÇÃO HISTÓRICA
}

\author{
Alessandro Octaviani \\ Mestrando em Ciência Política pela Universidade de \\ São Paulo. Diretor do Instituto de Direito ao Desenvolvimento \\ de Políticas de Emancipação Social - IDEPES
}

I. Introdução

1. O presente artigo tem como objetivo mapear questões referentes à importância da documentação histórica sobre a vida política do Centro Acadêmico XI de Agosto, da Faculdade de Direito do Largo de São Francisco.

2. Serão mencionadas as duas iniciativas mais importantes do gênero ocorridas em função da comemoração do centenário da entidade, neste ano de 2003: (i) a publicação do livro "A Heróica Pancada" e (ii) o enterro da "Arca do Centenário" (com o subseqüente descerramento de placa, no Território Livre, junto às outras históricas placas e à Tribuna Livre).

3. Após, serão ventilados alguns problemas de sociologia política que uma adequada documentação da História do Centro Acadêmico XI de Agosto poderia auxiliar a responder:

(i) as concepções políticas dos estudantes (o que iluminaria uma história dos movimentos sociais no Brasil);

(ii) a formação das redes político-jurídicas que se estruturam a partir do XI de Agosto (o que auxiliaria a compreensão da história das elites e burocracias do Brasil) e

(iii) os campos e resultados da socialização jurídica (o que permitiria uma melhor compreensão da disputa de hegemonia política no campo do Direito).

4. Finalmente, serão esboçadas algumas propostas concretas para a viabilização do procedimento de documentação do material historiográfico referente ao Centro Acadêmico XI de Agosto.

II. "A Heróica Pancada" e a "Arca do Centenário"

1. As comemorações do centenário trouxeram consigo específicas ações para a documentação da história da entidade. 
2. As duas mais significativas foram a publicação do livro "A Heróica Pancada" ' e o enterro da "Arca do Centenário"

3. Existe pesquisa e produção a respeito da história do XI, que pode ser encontrada esparsa nos escritos sobre a Faculdade de Direito do Largo de São Francisco, 2 nas biografias de algumas importantes personagens ${ }^{3}$ e no (sempre digno de nota, pelo denodo com que realizado) trabalho do Doutor Armando Marcondes Machado.

4. A gestão do ano de 2003 (grupo "Ruptura"), entendeu ser o caso de, por um lado, condensar a história dos atos políticos do XI em um único volume, e, por outro, oferecer ao historiador do futuro fontes físicas para a compreensão da vida material e simbólica do estudante de Direito do Largo de São Francisco, de hoje.

5. Destas opções nasceram o livro e a arca.

"A herôica pancada"

1. Para a realização do livro, foi contatado o Memojus - Instituto Brasileiro de Memória Jurídica e Social.

2. Com a contribuição, principalmente, Cássio Schubsky, Eunice Nunes, Sandor Resende e Herbert Carvalho, foram mobilizados inúmeros colaboradores, que puderam oferecer relatos orais e documentais sobre a história do XI nas últimas décadas.

3. O resultado é, primeiramente, delicioso.

4. Não há, para qualquer um que tenha se envolvido com quaisquer das atividades do XI ou da Faculdade, em seus tempos de universitário ou depois, como não se reconhecer em algumas daquelas páginas.

5. Além do relato dos fatos mais importantes e indispensáveis, houve também uma opção por privilegiar às ações e eventos realizados pelas gestões do Centro Acadêmico, principalmente no período de 1985-2002 (minimizando, por exemplo, a análise das disputas internas que o regem). Esta opção trouxe benefícios e prejuízos.

I. A heróica pancada: Centro Acadêmico XI de Agosto: 100 unos de lutas. Coordenação do projeto e edição Cássio Schubsky [pesquisa, reportagem e texto Eunice Nunes, Herbert Abreu Carvalho, Sandor Resende]. São Paulo: Memojus, 2003.

2. Cf., entre outros, Ana Luiza Martins e Heloísa Barbuy, Arcadas: História da Faculdade de Direito do Largo de São Francisco, p. 125. São Paulo: Melhoramentos/Alternativa, 1999. John Dulles, trad. Vanda Andrade, A Faculdade de Direito de São Paulo e a resistência anti-Vargas, pp. 15-36. São Paulo: EDUSP; Rio de Janeiro: Nova Fronteira, 1984. Teotonio Simões. Os bacharéis na política - A política dos bacharéis, parte I, capítulos II,III (o corpo discente), in www.teotonio.org/teses/bach/htm.

3. Cf., entre outros, Goffredo Telles Júnior, A Folha Dobrada - lembraņ̧as de um estudante. São Paulo: Nova Fronteira, 1999. 
6. Entre os benefícios, a possibilidade de fazer um texto corrido, repleto de informações, que demonstraria algum sentido de continuidade nas ações do XI, ainda que ocupado por grupos divergentes. ${ }^{4}$

7. Entretanto, ao não adentrar nas disputas internas (para permanecermos no primeiro ponto a ser ressalvado e suprido por pesquisas futuras), muito da história do XI, que é descontinuidade, conflito, denúncia dos limites dos projetos adversários, perde-se, fica oculto.

8. Explicitar as divergências, os grupos que as sustentam, os interesses e concepções profundas em que tais grupos se ancoram na disputa política pela hegemonia nacional (ainda quando amparados na ideologia da "autonomia", do "ensinismo/ internismo" ou da não-ideologia, por exemplo), como veremos adiante, pode ser um dos caminhos para alcançar uma adequada compreensão da história do XI.

9. Outro pontó a ser ressalvado diz com a própria forma de recolhimento de informações e as conseqüências para a redação.

10. Novamente pontuando em clave positiva a ampla rede de colaboradores manuseada ${ }^{5} \mathrm{e}$ a preocupação em ouvir os vários lados da mesma história, demonstrada pelos organizadores do volume, o tempo utilizado para as entrevistas orais, o razoavelmente curto tempo para a redação e a precariedade de grande parte da documentação encontrada (não-organizada, segundo quaisquer padrões científicos) trouxeram alguns problemas, dentre os quais destacamos um, a título de exemplo.

11. Na página 112, quando estão sendo narrados eventos referentes ao ano de 1997, encontra-se o seguinte parágrafo:

“Os professores Dalmo Dallari, Goffredo da Silva Telles Jr., Fábio Konder Comparato e Eros Roberto Grau, além de Celso Antônio Bandeira de Mello, promovem uma ação popular contra a privatização da Vale do Rio Doce, com apoio dos alunos, em ato na Sala dos Estudantes. Desse ato participa também o economista e dirigente petista Aloísio Mercadante."

4. Já não seria esse um tema para o pesquisador do futuro? As disputas, os textos lançados, comprovaria essa hipótese de "proximidade"? E as redes formadas a partir do XI, confirmariam, rechaçariam ou relativizariam essa proposta? Seria tal convergência apenas aparente, existindo de fato apenas um mesmo macrocampo discursivo, aquele instituído na normalidade democrática (da cidadania, dos direitos humanos, dos direitos sociais), permitindo, assim, uma aparente continuidade, que encobriria as diferenças de fato existentes, entre, por exemplo, um Partido do Máximo Tensionamento e um Partido do NãoTensionamento? Estaríamos, dentro da ordem democrática, frente a distintas forças em disputa pela hegemonia e conseqüente apropriação do excedente material e simbólico?

5. Rede da qual o autor do presente artigo teve a grande alegria de fazer parte. 
12. Estão misturados, neste parágrafo, três eventos distintos entre si:

(i) a lançamento do "Manifesto à Nação", de crítica ao uso de medidas provisórias pelo Governo Fernando Henrique Cardoso e progressiva erosão das instituiçōes democráticas do país (organizado pelos professores referidos e lido na Sala dos Estudantes, em ato cuja presidência dos trabalhos coube ao XI, gestão "Partido Acadêmico Autônomo");

(ii) promoção de ação judicial contra a privatização da Companhia Vale do Rio Doce, também organizada pelos referidos professores, com a inclusão de outros nomes;

(iii) ato realizado na Sala dos Estudantes pelo grupo "Rasgando o Verbo" de oposição à então gestão do XI, que contou com a presença do dirigente petista Aloîsio Mercadante e do professor Eros Grau, no qual, justamente, criticava-se a gestão do XI ("Partido Acadêmico Autônomo") por restar imobilizada em face do processo de privatização da Vale do Rio Doce.

13. Pesquisas futuras que contêm base de dados, corretamente catalogada, podem evitar tais imprecisões.

14. De qualquer maneira, mesmo com estas ressalvas, o resultado final de "Heróica Pancada" é extremamente positivo, sendo plenamente corretas as assertivas do representante do Memojus na cerimônia no Salão Nobre da Faculdade no dia 11 de agosto de 2003, de que este era apenas um primeiro passo para que "outras e divergentes histórias do XI pudessem vir a ser contadas"

\section{"A Arca do Centenário"}

1. A Arca do Centenário é a outra iniciativa em relação à documentação histórica do XI, articulada em função das comemorações.

2. AArca é um baú, no qual foram lançados inúmeros objetos escolhidos por alunos e ex-alunos (embalados a vácuo), que pudessem representar os modos de vida material e simbólico do atual estudante do Largo de São Francisco.

3. Segundo o regulamento de seu preenchimento, a Arca há de ser resgatada e aberta no próximo centenário da entidade.

4. A tradição de enterros de arcas ou baús no Largo de São Francisco é já antiga, podendo ser citados pelo menos dois célebres, anteriores aos da "Arca do Centenário"

5. O primeiro é o da "pedra fundamental", relatado na "Heróica Pancada" p. 83: 
"A pedra fundamental é lançada no final de outubro, em ato na Cidade Universitária. Na madrugada seguinte, mantendo a tradição da canalha acadêmica, estudantes furtam a pedra e a levam para o Largo de São Francisco, onde é enterrada. Na lápide da sepultura, o epitáfio: 'Quantas pedras forem colocadas, tantas arrancaremos - 30/X/1973' No sétimo dia, missa."

6. O segundo é o de um baú contendo a Constituição, assim descrito (idem, pp. 86-7):

"Em 1o. de abril de 1977, lançando mão do Al-5, o general Geisel fecha o Congresso e anuncia um pacote de medidas, incluindo eleições indiretas para um terço do Senado Federal e para o governo dos Estados nas eleições de 1978. Os 'eleitos' passam a ser chamados pela oposição de senadores $e$ governadores 'biônicos'

Todo o lero-lero do general-presidente de que vai promover a abertura política é negado pelos fatos. Hora de reagirem os estudantes do Largo de São Francisco. Na surdina, um punhado de alunos decide promover um ato público para enterrar a Constituição, morta pelo Pacote de Abril.

Arranjam-se vestes escuras, capuzes e tochas. Na falta de caixão, 'consegue$s e^{\prime}$ em um depósito municipal da empresa funerária, revivendo a tradição da canalha acadêmica, que furtara a estátua de José Bonifácio, o Moço, nos anos 30; os perus do professor Mazagão, em 48; a estátua $O$ idílio, em 66; , e a pedra fundamental da FDUSP na Cidade Universitária, em 73.

O professor Goffredo é convidado a falar no ato: 'Nessa noite, fiz um discurso em que disse: Ditadura é ditadura; democracia é democracia. Não confundiamos as duas coisas, que considerávamos distintas e separadas. Éramos pregoeiros incansáveis da democracia': relembra o mestre, 26 anos depois. Avisada, sem maiores explicações, de que um ato se realizaria no Território Livre, a imprensa aparece. E no dia seguinte divulga o Enterro da Constituição."

7. Assim, a "Arca do Centenário" veio a se juntar a, no mínimo, outros dois baús, contendo documentos históricos enterrados no Largo.

8. À diferença dos outros dois, entretanto, foi prevista para ser aberta, sendo desde o início concebido como material historiográfico. 
III. Interesses na documentação da história do XI

1. Esses dois procedimentos de documentação da história do XI, brevemente comentados acima, permitem iniciar uma reflexão mais ampla: quais são os problemas de sociologia política que tornariam obrigatórios maiores cuidados com a documentação histórica do Centro Acadêmico XI de Agosto?

2. Três âmbitos de problemas poderiam ser apreendidos de um modo muito mais correto, se houvesse uma boa documentação sobre a história do XI: (i) a história dos movimentos sociais no Brasil, particularmente do movimento estudantil; (ii) a história das elites do país (principalmente as redes e burocracias jurídico-políticas) e, numa perspectiva mais profunda, (iii) a partir destes dois esclarecimentos, a própria articulação do Direito à hegemonia política no Brasil.

III. i. História dos movimentos sociais no Brasil: concepções políticas dos estudantes

1. Uma adequada documentação historiográfica do XI poderia tornar muito mais ricas as pesquisas sobre os movimentos sociais no País, permitindo compreender um de seus principais (e ao mesmo tempo mais frágeis) eixos (talvez em função de sua difícil relação com a continuidade e acúmulo), que é o movimento estudantil.

2. As formulações, assimilação dos debates travados no País, capacidade de intervenção em contraste com capacidade de proposição e outras questões que intrigam os estudiosos dos movimentos sociais fatalmente sairiam enriquecidas com uma adequada documentação sobre o XI.

3. Durante a década de 90 , nas eleições para o Centro Acadêmico, tornou-se prática o lançamento de bem arranjadas cartas-programas, que enunciam princípios gerais, medidas concretas e os nomes dos integrantes das chapas adversárias.

4. As "cartas-programas" são um hábil documento a revelar as concepções em disputa, suas conexões com a política nacional, além do número de estudantes envolvidos.

5. Normalmente trazem uma análise da conjuntura nacional e, quando não o fazem, também esta opção é a de tônico sentido (suprimir a fala sobre algo é sempre dizer muito sobre o assunto...).

6. Para exemplificar a riqueza desse material para o historiador, traremos 
uma série de seis manifestações sobre conjuntura nacional, de um mesmo grupo político da Faculdade, que disputou as eleições do XI nos anos de 1992 a 1997. ${ }^{\circ}$

7. Não será objeto desse artigo a exegese dos textos, a análise de sua articulação ao momento do País ou a vinculação aos interesses e concepções profundas em disputa. A transcrição tem apenas objetivos demonstrativos da riqueza do matcrial historiográfico.

8. O grupo escolhido, "Rasgando o Verbo", se classificava "de esquerda"

9. Em 1992, a chapa contou com 22 candidatos, assim manifestando-se sobre a conjuntura nacional:

"POLÍTICA - Querenos que un Centro Acadêmico tenha opinião. Que possa, opinando e atuando frente aos temas socialmente relevantes, fomentar o debate politico na Faculdade. Neste sentido, defendemos:

- O fortalecimento do XI enquanto entidade participativa da sociedade civil, posicionando-se ao lado dos interesses populares e das camadas menos favorecidas da população;

Acompanhamento atento do Governo Itamar Franco, objetivando a que se garanta: I.) Respaldo aos anseios populares; 2.) Volta do crescimento econômico, efetivação de uma política de pleno emprego e distribuição de renda; 3.) concretização das reformas estruturais necessárias à construção de uma sociedade mais justa igualitária, incluindo reformas agrária e urbana; 4.) Ensino público, gratuito e de qualidade em todos os níveis; 5.) Apoio à autonomia dos organismos públicos de fontento à pesquisa científica;

- A democratização do Judiciário e do acesso à justiça;

- A democratização dos meios de comunicação;

- Atenção especial será dada à Reforma Constitucional, inclusive no referente ao plebiscito sobre forma e sistema de governo. Fundamental é a definição dos limites da revisão, a fim de que sejam preservadas e aperfeiçoadas todas as garantias democráticas e sociais presentes no texto atual." (Carta-programa "Rasgando o Verbo - Oposição XI" pp. 3-4)

6. Outras opções poderiam ser tomadas, como a transcrição de concepções, para os mesmos anos, de vários grupos distintos, ou centrar-se em apenas dois grupos. A opçāo por apenas um grupo em vários anos privilegia a percepção do cambiamento e Inanutenção de concepções que um inesıno grupo apresenta. De qualquer maneira, trata-se apenas de $\iota m$ dos vários inanuseios do material disponível ao historiador. 
10. Em 93, com 25 candidatos, este é consenso sobre conjuntura nacional:

\section{"CONJUNTURA NACIONAL}

O C.A. XI de Agosto não pode se ater aos velhos dogmas do movimento estudantil. Não cabe levantar apenas bandeiras de luta e palavras de ordem como base de atuação política. Não temos o ônus de nos declararmos oposição global a qualquer governo, federal, estadual ou municipal. É nuito simples declarar-se contra ou a favor de determinada administração. Devemos nos manifestar quanto à atuação dos governos nas mais diversas áreas, atuando no dia-a-dia das Administrações.

Esta mudança de perspectiva visa evitar atuar numa entidade da sociedade civil como se faria em um partido político. Isto não quer dizer deixar de nos manifestarmos. Estamos ao lado dos econômica e socialmente excluidos, dos que lutam por uma sociedade justa e por uma política de distribuição de renda. Vivemos um periodo de impasse. A linha econômica adotada pelo Governo Itamar Franco pouco se diferencia daquela trilhada pelo ex-presidente Collor: O processo de privatização desenfreado e sem critérios nítidos continua, as estatais são vendidas a preços bastante inferiores ao valor real, utilizando-se de moedas podres, não contribuindo para a solução dos problemas nacionais. Os índices de desemprego continuam aumentando e a política salarial não atende às mínimas necessidades da população, atendendo à lógica do capitalismo brasileiro, extremamente concentrador de renda.

A desastrosa política educacional adotada pelos governos Itamar, Fleury e Maluf acelera o processo de deterioração das escolas públicas e do ensino, tornando cada vez mais distante o ideal de um ensino público gratuito e de qualidade. $\dot{E}$ especialmente lamentável o descaso do governo estadual pela questão salarial enfrentada pelos professores da rede pública.

Somos favoráveis à realização de uma ampla reforma agrária e urbana que permita ao Brasil tomar as rédeas de seu desenvolvimento econômico. Defendemos a necessidade de mudanças estruturais. Nos repugna a falta de interesse da classe política brasileira em construir um projeto original para o país.

Preocupação especial com a questão ambiental. A prática de uma política de desenvolvimento sustentado para as áreas ecológicas ameaçadas deve ser um dos principais objetivos de qualquer governo.

Fortalecer a Campanha Contra a Fome, promovida pelo sociólogo Betinho, 
através de palestras e arrecadação de alimentos. É essencial encontrarmos una solução real para o problema da fome e da miséria." (Carta-programa “Rasgando o Verbo - Oposição XI" pp. 4-5)

8. Na eleição de 94 , o grupo apresenta uma chapa com 26 candidatos, manifestando-se nos seguintes termos sobre conjuntura nacional:

\section{“CONJUNTURA NACIONAL}

Colocar-se numa postura crítica ou favorável ao governo federal e estadual eleitos em 94 não é uma posição a ser tomada a priori pela Rasgando o Verbo 95. Fiscalizando, buscando transparência e colaborando, a chapa pretende manifestar-se se forem tomadas atitudes econômicas, sociais ou políticas que firam ou passam vir a ferir alguns princípios tais como a justiça social, a idoneidade e a honestidade na administração pública.

Cumpre darmos continuidade à luta pela democratização dos meios de Comunicação. Através da Rádio XI, que voltou a funcionar em 94, vemos um canal para divulgação dessa campanha.

Vemos também a necessidade de fortalecer a Ação da Cidadania contra a fome e a miséria pela vida, promovida pelo sociólogo Betinho. É fundamental que se encontre uma solução real para o problema da fome sem concordar com uma organização e de difícil acesso da Campanha. Trazer esta preocupação para a Faculdade é fundanental.

Somos radicalmente contra a discriminação racial, social, sexual e econômica (vedadas pela Constituição de 1988, mas cotidianamente praticadas).

Contra a pena de morte, contra o plebiscito sobre a pena de morte.

A questão do aborto envolve princípios éticos, morais, religiosos e uma legislação taxativa passível de ser discutida. Frente a unta conjuntura na qual não há qualquer tipo de planejamento familiar; na qual a desinformação é generalizada e o mímero de mortes e lesões causadas em decorrência dos numerosos abortos clandestinos, a Rasgando o Verbo aposta na informação e também na descriminalização do aborto sem, contudo, prescindir de debates interdisciplinares.

Reputamos imprescindivel a definição legal de usuário e traficante de drogas, distinguindo-os. A reforma da Parte Geral do Código Penal deve ser acompanhada de perto. Posicionamo-nos, criticamente, frente à postura do 
Governo quanto à questão ambiental. A prática política de desenvolvimento sustentada para as áreas ecológicas ameaçadas deve ser um dos principais objetivos de qualquer governo.

A moderna concepção da divisão de poderes faz necessária uma análise das funções do Poder Judiciário. É inegável que este tem una função social a cumprir. No Brasil, este poder não tem se mostrado capaz de solucionar novos conflitos oferecidos pela sociedade. Adotou-se um modelo dogmático, incompativel com a realidade social, cujos moldes são delimitados por um interventor e pela pluralidade de fontes paralelas emanadoras do direito.

A busca de soluções para os conflitos deve garantir uma igualdade real e não meramente formal, assegurada pelos Códigos. O excessivo normativismo deve ser combatido.

Polarizada, a questão do controle externo do Judiciário envolve argumentos plausíveis (já que sabemos que atrás de sua aparente neutralidade se escondem influências políticas efetivas de diversos grupos de pressão) e outros descabidos (como controle sobre a decisão de mérito do juiz). Na ordem do dia, não podenos nos esquivar de discutir essa questão na Sala dos Estudantes.

Também é atual o novo Estatuto da OAB. A Rasgando o Verbo entende necessária a realização de um fórum de debates que questione a conveniência da modificação do estatuto. Mostramos, desde logo, nosso desprezo pelo corporativismo. A Justiça Militar representa, muitas vezes, os conhecidos 'Tribunais de Exceção' a justiça 'comprometida', ad hoc. Posicionamo-nos pela sua extinção bem como pela desmilitarização da Polícia.

A defesa de uma sociedade justa e de uma política de distribuição de renda faz parte de nossa linha de atuação. Somos favoráveis a uma ampla Reforma Agrária e Urbana que possam assentar a grande massa da população carente de moradia, entre outras coisas. A mudança deve ser estrutural." (Cartaprograma "Rasgando o Verbo - Ousar Lutar, Ousar Vencer" pp. 4-5)

9. Em 1995, a chapa apresenta 31 candidatos, e sua avaliação da conjuntura nacional é a seguinte:

"Conjuntura: O Centro Acadêmico XI de Agosto deve manter sua tradição de lutas posicionando-se sobre os mais variados tenas da política nacional. $A$ Revolução de 32, a campanha do 'Petróleo é nosso', a luta contra as ditaduras 
(a de Getúlio Vargas e a que sucedeu o Golpe de 64), a campanha pela redemocratização do país são feitos que tornaram o XI de Agosto uma importante entidade da sociedade civil.

Atualmente, o XI vem se posicionando claramente contra a impunidade, como en campanhas pelo fim da Justiça Militar e pela responsabilização do Estado pelas mortes e desaparecimentos políticos. Uma entidade que se pretenda atuante deve ter idéias sobre rumos de seu próprio país. Para tanto, estabelecemos projetos a níveis federal, estadual e municipal.

Para a realização de qualquer debate, minimamente sério, é necessário entender os novos marcos mundiais, que representam uma mudança. Vivenos em uma época de profundas transformações.

Globalização, unificação de todos os mercados nundiais, extinção das barreiras econômicas de circulação do capital e de mercadorias em nivel mundial, desenvolvimento de novas tecnologias, a reorganização do mundo do trabalho, a conseqüente concentração urbana são as características das mudanças.

E para onde vamos? A idéia da aldeia global se estreita a cada dia. $O$ ritmo do mundo se acelera e as referências de tempo e espaço se comprimem.

$O$ modelo de globalização neoliberal tem sido a alternativa majoritária na América e em alguns países da Europa.

Esse modelo caracteriza-se pela abertura unilateral das economias, diminuição do papel do Estado com privatizações e redução dos investimentos nas áreas sociais, desregulamentação das relações sociais. Tudo monitorado pelo sabor das regras do mercado.

Para os países subdesenvolvidos, cujas pontencialidades interessam ao mercado mundial, restam duas alternativas: adequar-se a esse modelo, cadastrando-se como sócio-minoritário ou apostar na possibilidade de uma inserção ativa nesse contexto global.

O primeiro caminho implica exclusão social, suplantando o conceito de cidadania pelo de comprador em potencial. Não há lugar para quem não for consumidor e, assim 2/3 da população, que constituem o terceiro mundo (África, América do Sul, parte da Ásia), sofrem os efeitos duros deste processo excludente. Conjuntura Nacional: A busca de estabilidade econômica está sendo colocada num plano superior ao da resolução dos graves problemas pelos quais passa o país, com corte de investimentos nas áreas sociais, recessão, desemprego e manutenção das altas taxas de juros. 
A aliança PSDB-PFL, neste atual contexto, não é absurda, é lógica. Está nítido que não tratava de coligação eleitoral, mas de ıma união de forças que aspira!n à aplicação de um projeto. É a tentativa de unir os interesses da elite oligárquica agrária do PFL nordestino às exigências do capitalismo mundial, ao qual estão integrados tanto FHC quanto ACM.

Colocar-se numa postura crítica aos governos eleitos será uma postura da Rasgando o Verbo no XI de Agosto. Fiscalizando, exigindo transparência, debatendo e discutindo as iniciativas de cunhos político, econômico e social. Ousamos acreditar que é possível construir o segundo caminho. O país precisa de reformas estruturais, porque precisa eliminar a pobreza, os 32 milhoes de miseráveis, aprofundar a democracia e dimimuir a violência. A defesa de uma sociedade justa, democrática e cidadã faz parte de nossa linha de atuação." (Carta-programa "Rasgando o Verbo - transformar a sociedade, transformar o direito". pp. 5-6)

10. Em 1996, o grupo apresenta uma chapa com 44 candidatos, e a seguinte avaliação da conjuntura nacional:

"CONJUNTURA: Compreender a realidade em que vivemos e trabalhar para sua transformação em uma sociedade justa e democrática é papel fundamental de todo estudante de direito.

A educaf̧ão política no XI de Agosto deve envolver uma visão global e constante da realidade brasileira. É preciso umia atuação cotidiana, séria e corajosa, capaz de envolver os alunos na participação e no debate político.

Ter clareza sobre os projetos propostos hoje para o Brasil, e se posicionar a respeito de suas diversas implicações e consequiências, deve ser a postura do grupo que deseja estar no XI, construindo a história da entidade e de nosso pais.

A atual gestão, infelizmente, não vê as coisas desse modo. Teve uma atuação omissa, apenas tangenciando alguns problemas da realidade brasileira, sem contextualizá-los. A falta de menção à maioria dos pontos que aqui serão levantados revela uma postura apática em relação ao papel do XI de Agosto. Colocar-se de maneira crítica em relação aos governos será uma postura da Rasgando o Verbo no XI de Agosto, procurando debater e aprofundar as soluções apresentadas. 
Conjuntura Nacional: O atual governo reiniciou a implantação do projeto neoliberal no Brasil, caracterizado pela abertura abrupta de nossa economia, pela privatização das estatais, por proposta de desconstitucionalização de direitos e garantias, sempre ancorando-se na estabilidade inflacionária, seu grande trunfo político.

Longe de negar a importância que a manutenção da inflação em taxas baixas pode ter, cabe-nos apontar que o modelo adotado traz consigo graves conseqüências, como o aumento da dívida pública, a desindustrialização e a queda do nível de emprego no país, agravando a crise social que temos atravessado. O enfrentamento à miséria, à fome, à violência deve passar por una política de distribuição de renda e geração de empregos, construindo una sociedade justa e cidadã. Nossa atuação será baseada nos seguintes pontos nacionais:

Reforma agrária é un problena de justiça social e econômica para o pais. A violência no campo é fruto da concentração de terras no país. Somos favoráveis à realização de uma ampla Reforma Agrária, que possa assentar a grande massa de população sem terra.

O Judiciário brasileiro deve estar mais próximo dos conflitos em nossa realidade. De um lado, são necessárias medidas que proporcionem um amplo acesso à justiça. De outro, é preciso reduzir o excesso de normativisno, que muitas vezes impede a obtenção de una solução mais justa. Além disso, pretendemos ampliar a discussão sobre o controle externo.

O Plano Diretor de Reforma do Aparelho do Estado, proposto pelo governo federal, transfere às 'organizações sociais' entidades de direito privado, as responsabilidades sobre os rumos da saúde e da educação. Ao contrário disso, defendemos um projeto de democratização do Estado e da sociedade, incentivando a participação popular na definição das principais diretrizes.

- A questão da violência precisa ser encarada de frente. Fortalecer os direitos individuais e coletivos, respeitar os Direitos Humanos, combater a exclusão social, o narcotráfico e as organizações paraestatais são ações essenciais para a redução da violência.

Defendemos a denocratização dos meios de comunicação, como caminho essencial para a prática da democracia. A barganha política pelas concessões de canais de rádios e TVs precisa acabar, tendo em vista a enorme importância das comunicações na sociedade moderna." (Carta-programa "Rasgando o Verbo - A opção de mudança” pp. 7-8) 
11. Em 1997, o grupo lançou uma chapa com 58 candidatos, assim relatando sua opinião sobre a conjuntura nacional:

"XI de Agosto e conjuntura nacional: 'A racionalidade econômica do neoliberalismo já elegeu seu principal inimigo: é o Estado Democrático de Direito' (Prof. Eros Grau)

O C.A. XI de Agosto tem um papel histórico no que tange às questões de âmbito nacional: além de trazer o debate para a faculdade e posicionar-se sobre os projetos para o país, deve construir; no cotidiano da faculdade, as condições para que os universitários interfiram no futuro da sociedade brasileira.

A discussão e o posicionamento político claro deve ser a marca da gestão ao longo do ano, e não-somente em determinado evento, campanha, ou fatos escandalosos noticiados pela midia. É um processo que deve ser construido em nosso dia a dia. 'Brasil, Mostra tua cara'

Hoje, após alguns anos de implementação do modelo neoliberal de Estado e sociedade pelo governo, podemos analisar com maior clareza algumas de suas conseqüiencias. Antigos problemas que assolam a nação ainda não foram solucionados, como a desigualdade econômica e social, a reforma agrária e a construção de unua real democracia.

Estamos nos afastando rapidamente do modelo de Estado idealizado pelos constituintes, de 1988, em função do compromisso assumido com um tipo de inserção subordinada ao processo de globalização.

Economicamente, assistimos ao aumento dramático do desemprego, à desindustrialização e à perda do controle de setores estratégicos da economia para investidores externos, públicos ou privados, como demonstrou o caso da Vale do Rio Doce.

Além disso, a racionalidade econômica exigida por este projeto de país não admite alguns 'empecilhos' Neste contexto, o Executivo passa a 'legislar' através de medidas provisórias, e busca-se a homogeneização ideológica do Judiciário, através da súmula vinculante.

O silêncio eloqüiente: dentro deste quadro, devemos nos perguntar a respeito da atuação da atual gestão do XI. Optando por não se posicionar a respeito da maioria das questões aqui elencadas, não contestam o projeto neoliberal, corroborando-o em suas principais limhas. Seu silêncio no caso da Vale, para citar apenas um exemplo, é eloquiente. 
Uma gestão realmente preocupada com o país e com os rumos da universidade pública deve posicionar-se politicamente, além de atuar para que o aluno interfira, exercendo seu papel de cidadão, nas principais pautas colocadas.

A alternativa democrática: Papel Histórico do XI

As alternativas ao projeto hoje hegemônico devem passar pela democratizą̧ão do Estado, por una política de emprego e por uma alternativa não-subordinada de inserção à globalização. Para tal, o aprofundamento da democracia é essencial, ampliando-se cada vez mais o espaç̧o de debate entre a população e os dirigentes do Estado. É a superação da representação pela participação. É para defender tal projeto em conjunto com os alunos que queremos estar no CA. O nosso XI não pode ficar ausente neste momento da história do país." (Carta-programa "Rasgando o Verbo - A opção democrática" p. 4).

12. Somente esta amostra de matcrial historiográfico já seria suficiente para iniciar uma série de questionamentos, sobre o diagnóstico que o grupo desenvolveu sobre as políticas econômicas implementadas, sua relação com o Direito; as noções de democracia subjacentes ao discurso; a mudança no tratamento dos governos, etc.

13. Tais problemas ganhariam em riqueza se lossem cruzados dados, por cxcmplo, relerentes ao resultado das eleições, conlïguração sócio-econômica do alunado da graduação (universo de sócios do XI, lembrando-se que os ex-presidentes da entidade até o ano de 1984 têm dircito a voto, sendo que muitos deles o exerceram na década de 90), cvolução do quadro cleitoral do município de São Paulo, do Estado e da União.

III.ii. A história das elites do País (principalmente as redes e burocracias jurídicopolíticas)

1. Oliveiros Ferreira, em sua herética interpretação do pensamento de Gramsci contida em "Os 45 cavalciros húngaros" 7 afirma que em Marx já havia a percepção de que as elites possuem redes internas.

2. Tal cstaria claro no " 18 do Brumário de Luís Bonaparte" quando são analisados os republicanos do Jornal "Nacional", no início do descrito movimento de derrocada de toda dignidade política da França c ascensão da borra social, liderada pclo carismático porém degradado sobrinho de Napoleão.

7. Os 45 cavaleiros húngaros - uma leitura dos Cadernos de Gramsci. Brasília/São Paulo: UnB/ Hucitec, 1986. 
3. Para Oliveiros Ferreira, interessado em afirmar que Marx emprestava grande signilicado à posição social, mais do que à propricdade, na delïnição da fração de classe, serão os valores culturais os liames fundamentais entre os membros das redes: "Não era a comunidade dos interesses derivados das condições de produção que formava a coterie, mas sim o compartilhar as idéias republicanas e o desfrutar um mesmo estilo de vida, que se identifica e determina por aquilo que o grupo considera seu componente típico do destino vital humano condicionado por uma estimação social especifica'(Weber)." 8

4. Em Gramsci, de fato, há uma grande prcocupação com as elites, scu interno compartilhamento de concepções e projetos, dialeticamente vinculados à apropriação do excedente e à organização da produção material.

5. No campo não-marxista também houve forte desenvolvimento dos estudos sobre as elites e as redes.

6. Uma adequada documentação sobre o XI renderia boas pesquisas sobre o tema no Brasil.

7. As lealdades construídas durante os anos universitários mantêm-se após o curso? Os grupos políticos são um elemento de socialização apto a forjar laços que transcendam os bancos da faculdade? Nos governos, na vida acadêmica, na Magistratura, na Advocacia, no Ministério Público, haveria a confirmação de tais laços? Ainda que existam laços que levem a redes, qual seu fundamento mais forte, amizadc, nostalgia ou concepções políticas?

III.iii. Articulação do Direito à hegemonia política no Brasil

1. Bem respondidas as duas ordens de questionamentos acima insinuadas, estaríamos próximos de compreender importantes aspectos da disputa pela hegemonia política no campo jurídico.

2. Identificadas as concepções políticas dos estudantes, os interesses profundos nos quais se ancoram, percebidas as conseqüências das práticas de socialização política em uma expressiva "coterie" de nossas elites, poder-se-iam verificar importantes mecanismos na dialética da hegemonia.

3. Os programas defendidos durante a universidade são assimilados de modo a se contrapor às concepções dominantes? O grupo "Rasgando o Verbo" por

8. Idem, p. 27. 
exemplo, forjou estudantes capazes de apresentar outra postura perante o Direito, que não a positivista (em sua versão mais privatista, principalmente) ou a neoliberal? Ainda que tenha formado "estudantes" com tal capacidade, esta formação resistiu a outros processos de socialização jurídica, posteriores? As redes jurídicas formadas após o momento universitário apresentam quais concepções? A quais interesses tais concepções estão vinculadas?

4. Estas questões permitiriam verificar com grande sofisticação os sentidos e a intensidade de força de mudança/conservação apresentados pelo campo jurídico no Brasil.

5. Até se pode revelar que este é um campo apto a ser transformado, por práticas ilustradas e críticas, alterando-se, assim, a própria hegemonia do processo social.

6. Por outro lado, poder-se-ia descobrir que este é um campo insensível ao tipo de prática política levado a cabo pelos grupos sociais pesquisados. Talvez daí resultassem outras hipóteses, cheias de conseqüências práticas, como a autonomia dos sistemas, ou a subordinação do Direito à Economia (o que, no tempo do consumismo como fé coletiva, é hipótese ainda mais dramática).

IV. Proposta de documentação

1. Deste preliminar levantamento de questões, percebe-se a importância da adequada documentação historiográfica do XI de Agosto.

2. O material sobre o XI de Agosto encontra-se em diversos repositórios, tendo sido absolutamente louvável o trabalho do Memojus em sua localização.

Junção de arquivos individuais pretéritos

3. Entretanto, um imenso e rico material sobre o XI pertence aos arquivos pessoais e individuais dos que com ele se envolveram, na rubrica de "recordações pessoais", "Memórias do Tempo de Faculdade", etc.

4. Esses arquivos individuais geralmente cobrem somente alguns anos, muitas vezes não chegando a cobrir sequer todos os anos em que o estudante esteve na Faculdade.

5. Seu conteúdo é geralmente composto pelos jornais acadêmicos, textos de ocasião, manifestações sobre fatos contemporâneos, polêmicas internas, etc. 
6. A junção de vários desses arquivos cobriria uma extensa área temporal, trazendo um panorama extremamente vivo e detalhado da vida política universitária do período.

Gravações em áudio e vídeo dos eventos da Sala dos Estudantes

7. Para além da sistematização dos arquivos individuais pretéritos, caberia uma estratégia de documentação dos fatos futuros, com coleta periódica e sistemática do material escrito divulgado na Faculdade.

8. Além disso, o registro em áudio e vídeo dos eventos ocorridos na Sala dos Estudantes, com posterior transcrição e arquivamento, é outra medida que tornaria o registro histórico bastante eficaz.

9. Imagine o leitor se pudesse hoje acessar o vídeo com os debates travados durante a Constituinte, na Sala dos Estudantes, ou o pronunciamento do XI de Agosto em favor da candidatura Lula em 1994 (em ato no qual se pronunciaram, além do representante do XI e do candidato Lula, os intelectuais Paulo Freire, Ariano Suassuna, Marilena Chauí, Fábio Konder Comparato, Milton Santos e muitos outros. Imagine o historiador do futuro podendo ver, na Sala dos Estudantes, Zé Celso interpretando o Brasil ou o ministro Sérgio Motta afirmando a realização do programa de privatizações das telecomunicações, mas mantendo o compromisso com as rádios comunitárias...

10. Esses são apenas alguns fatos que, registrados, serviriam de rico material ao pesquisador do futuro. Fatalmente o leitor há de elencar inúmeros outros, muito mais importantes do que estes... O que, felizmente, só realça a necessidade da proposta.

Informação "pública, democrática e de qualidade"

11. Uma iniciativa como esta seria viabilizada, acaso houvesse um adequado concerto entre vários agentes, como antigos alunos, diretoria do XI, diretoria da Faculdade de Direito da Universidade de São Paulo, professores de história, etc.

12. Garantida a informação "pública, democrática e de qualidade" estariam garantidos também os pressupostos para a pesquisa séria e crítica, comprometida com a revelação das íntimas articulações de nossa história.

São Paulo, setembro de 2003. 